\title{
WAYFINDING E SUA IMPORTÂNCIA PARA ELABORAÇÃO DE INFOGRÁFICOS PARA DESLOCAMENTO EM UM CAMPUS UNIVERSITÁRIO: UMA REVISÃO DE LITERATURA
}

\section{WAYFINDING AND ITS IMPORTANCE IN SETTING INFOGRAPHICS FOR DISPLACEMENT IN A COLLEGE: A LITERATURE REVIEW}

\author{
Letícia Rosa Guará ${ }^{1}$, graduanda em design \\ André Leonardo Demaison², M.Sc. \\ (1) Universidade Federal do Maranhão \\ e-mail: leticia_guara@hotmail.com \\ (2) Universidade Federal do Maranhão \\ e-mail:demaison@gmail.com
}

Wayfinding, infografia, sinalização

Este artigo propõe uma revisão teórica sobre o design da informação e o wayfinding design, e como estes conceitos podem ser aplicados juntos para resolver problemas de deslocamento e percepção espacial em um campus universitário. A partir destes conceitos, apresenta ideias e recomendações para a construção de um infográfico de auxílio à navegação dentro do campus.

\section{Wayfinding, infographic, signage}

This scientific article proposes a theoretical review about information design and wayfinding design, and how these concepts can be applied together to settle problems of spatial perception and displacement in a College. From these concepts, to come up with ideas and recommendations for the construction of a navigation aid infographic inside the College. 


\section{$16^{\circ}$ \\ ERGODESIGN USIHC CINAHPA}

$16^{\circ}$ Ergodesign - Congresso Internacional de Ergonomia e Usabilidade de Interfaces Humano Tecnológica: Produto, Informações Ambientes Construídos e Transporte

$16^{\circ}$ USIHC - Congresso Internacional de Ergonomia e Usabilidade de Interfaces Humano Computador

CINAHPA | 2017 - Congresso Internacional de Ambientes Hipermídia para Aprendizagem.

\section{1-Introdução}

A Cidade Universitária Dom Delgado está localizada em uma área de 1.013.872,00 metros quadrados e abriga 48 cursos de graduação e 29 cursos de pós-graduação stricto sensu, além de um Restaurante Universitário, ginásio, piscina, quadra de esportes, rádio, TV Universitária, bibliotecas, auditórios, laboratórios e vários outros espaços que compõem a estrutura física da Universidade Federal do Maranhão.

Com toda esta estrutura construída, torna-se essencial ter um sistema de sinalização adequado, tanto internamente quanto externamente, além de se buscar outras estratégias que permitam o melhor conhecimento da estrutura física do local, suas rotas, serviços oferecidos e que ofereça uma noção do espaço total da Universidade.

O design da informação atua exatamente neste processo de transmissão de mensagens, de modo a facilitar a compreensão através da organização, codificação e apresentação de informações.

HORN (1999) define o design da informação como "[...] a arte ou a ciência de preparar a informação de maneira que ela possa ser usada pelos indivíduos com mais eficiência e efetividade".

Além disso, ele enumera três objetivos para o design da informação. São eles:

1. desenvolver documentos que sejam compreensíveis, de assimilação rápida e precisa, e facilmente convertidos em ações efetivas;

2. projetar interações fáceis, naturais e prazerosas para interfaces homem-computador;

3. auxiliar pessoas a encontrar caminhos em espaços tridimensionais com conforto e facilidade, especialmente em ambientes urbanos, mas também em espaços virtuais. (Horn, 1999)

Do ponto de vista da produção, o processo do Design da Informação ocorre em dois momentos distintos: a organização da informação e a codificação-implementação de sua apresentação visual. (Gianella \& Souza, 2015: 49)

Seguindo o proposto, é então necessária uma prévia coleta e posterior seleção de informação, para então planejar de que forma elas serão apresentadas.

O resultado desse processo é uma informação clara e fácil de ser compreendida, que pode ser encontrada em diversos materiais de uso cotidiano, como diagramações digitais e impressas, manuais de instrução, tabelas e gráficos, bulas de remédio, mapas, infográficos, sinalizações, interfaces digitais e vários outros.

Dentro dessa lista, as representações esquemáticas (que incluem mapas e infográficos) são as que melhor se encaixam no estudo em questão, por conterem as informações relativas a espaço e navegação em ambientes construídos. É a estratégia que melhor se adequa às necessidades descritas e por ser um recurso gráfico objetivo, de fácil compreensão e que pode ser aplicado em um curto prazo, com custos menores.

Por meio do infográfico, o usuário pode ter conhecimento de onde se encontra em relação ao espaço geral da UFMA, estabelecer suas próprias rotas para chegar ao local desejado, se informar sobre os percursos dos ônibus e suas paradas, e saber a localização de prédios e serviços importantes, como bancos, auditórios, prefeitura de campus, hospital etc.

Para Rocha \& Garone (2014), “A infografia é a representação visual de uma informação. Este carrega em si conteúdo complexo e de difícil compreensão imediata. O infográfico então é elaborado com a função de organizar esse conteúdo, hierarquizando as informações e as transmitindo visualmente de maneira clara e objetiva". (Rocha \& Garone, 2014)

Para desenvolvê-lo, é importante o conhecimento sobre wayfinding, sendo um conceito que pode ser compreendido como "navegação" ou, segundo O'Grady (2008), um termo que "descreve a maneira como um indivíduo se orienta em um 
$16^{\circ}$ Ergodesign - Congresso Internacional de Ergonomia e Usabilidade de Interfaces Humano Tecnológica: Produto, Informações Ambientes Construídos e Transporte

$16^{\circ}$ USIHC - Congresso Internacional de Ergonomia e Usabilidade de Interfaces Humano Computador

novo ambiente, e como os processos cognitivos são usados para determinar e seguir rotas, passando de um ponto a outro." (O’GRADY, 2008. p.72)

De modo simplificado, wayfinding então é o processo que faz o indivíduo ao localizar-se dentro de um espaço e que o faz tomar uma direção de acordo com o local que deseja alcançar.

Em um contex to tão diverso como o de uma Universidade, é essencial que a informação apresentada seja clara e compreensível, permitindo a tomada de decisões de maneira rápida e fácil por todos que a frequentem.

\section{2- O wayfinding: uma breve conceituação}

Como já dito anteriormente, wayfinding significa, em uma tradução literal, "encontrando caminhos". De acordo com a SEGD (Society for Experiential Graphic Design), wayfinding se refere a sistemas de informações que guiam pessoas por ambientes físicos e aprimoram sua compreensão e experiência em relação ao espaço. Para que isto aconteça, é necessário que ocorra vários processos na mente daquele indivíduo que deseja se localizar e se locomover pelo espaço. É preciso que haja uma leitura contínua do ambiente, seu reconhecimento e a escolha de um caminho. Estes processos ocorrem em nível cognitivo. Os sistemas de wayfinding visam aprimorar a experiência das pessoas ao navegar no ambiente construído. (Costa, 2014). De acordo com Velho (2007), o foco do wayfinding é "o planejamento espacial e a comunicação".

Pode-se perceber, então, que wayfinding não se aplica somente a problemas de navegação em ambientes construídos, mas a todo tipo de ambiente, seja virtual ou real, em que é necessário se localizar de alguma forma, e procurar por alguma localização a partir daquela em que se está. Para Pullman (2009, apud Costa, 2014), as pessoas precisam de wayfinding ao sair do metrô no meio da cidade, ao sair de um elevador em um prédio desconhecido, procurando um artigo em uma revista ou navegando em um website.

\section{1- Necessidades e importância de bons sistemas de wayfinding}

Segundo Arthur e Passini (1992, apud Pacheco \& Fukushima, 2012) o processo de um projeto de wayfinding é diferente de simplesmente colocar placas de sinalização, é um processo que visa entender o local e verificar as necessidades do usuário, fazendo com que o mesmo opte pela melhor rota e que vai satisfazê-lo com mais facilidade.

De acordo com os autores, é importante primeiro entender como se dá a orientação espacial dos frequentadores para em seguida organizar as informações levando em conta todos esses processos.

Para isso, entrevistas com usuários são de extrema importância para o entendimento de como suas decisões são tomadas e quais dificuldades apresentam.

Gibson (2009) complementa ao dizer que é de responsabilidade do wayfinding designer melhorar a experimentação das pessoas que utilizam esses espaços, a fim de fazer com que saibam onde estão, como transitar em um determinado local, o que acontece nesse local e como sair dele.

\section{3- Sinalização}

Para Munari (2006), um sistema de sinalização é uma forma de comunicação visual intencional, pois utiliza códigos, sinais, cores, formas e imagens para transmitir uma determinada informação que precisa ser entendida pelos usuários.

A sinalização tem o intuito de informar, orientar, e direcionar o indivíduo que deseja se localizar e/ou tomar uma direção.

Chamma \& Pastorelo (2007, apud Rocha \& Garone, 2014) definem sinalização como "associação de formas escultóricas informativas" cuja característica mais importante é transmitir informações para os usuários de um espaço físico.

No contexto de uma Universidade é fundamental que sua sinalização seja eficaz e confortável para seus visitantes, visto que a cada semestre dezenas de novos alunos visitam seus espaços pela primeira
Realização:

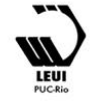




\section{$16^{\circ}$ \\ ERGODESIGN USIHC CINAHPA}

$16^{\circ}$ Ergodesign - Congresso Internacional de Ergonomia e Usabilidade de Interfaces Humano Tecnológica: Produto, Informações Ambientes Construídos e Transporte

$16^{\circ}$ USIHC - Congresso Internacional de Ergonomia e Usabilidade de Interfaces Humano Computador

CINAHPA | 2017 - Congresso Internacional de Ambientes Hipermídia para Aprendizagem. vez e necessitam de uma informação segura, rápida e compreensível.

\section{2- O campus do Bacanga}

A Universidade Federal do Maranhão, fundada em 21 de Outubro de 1966, conta hoje com 8 campi espalhados pela ilha de São Luís e demais cidades do continente, e tem no seu campus do Bacanga, na capital maranhense, a sua principal unidade.

Na UFMA são oferecidos 19 mestrados acadêmicos, 3 mestrados profissionais e 5 doutorados acadêmicos, além de 2 doutorados em rede, totalizando 29 cursos de pós-graduação stricto sensu.

O Campus de São Luís oferece 48 cursos de graduação, distribuídos em quatro Centros Acadêmicos: o CCSo - Centro de Estudos Sociais, o CCH - Centro de Ciências Humanas, o CCBS Centro de Ciências Biológicas e da Saúde e o CCET - Centro de Ciências Exatas e Tecnologia. além disso, oferece outros serviços tanto aos estudantes e servidores quanto à comunidade, como bancos, lanchonetes, recarga de carteiras de estudante, esportes, bibliotecas e restaurante.

A sinalização existente é feita a partir de placas acima das vias e totens com nomes dos prédios. Não há uma sinalização central, nem nenhum tipo de auxílio para encontrar serviços básicos. Visitantes em sua grande maioria se orientam a partir de informações pedidas aos transeuntes.

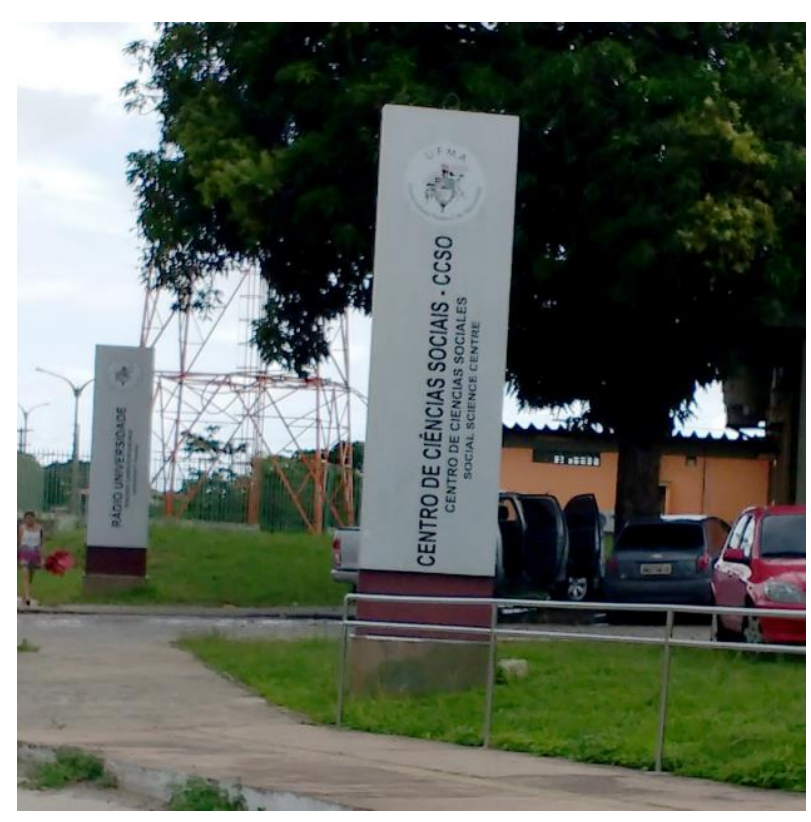

Figura 1- Totens de sinalização. Fonte: arquivo pessoal

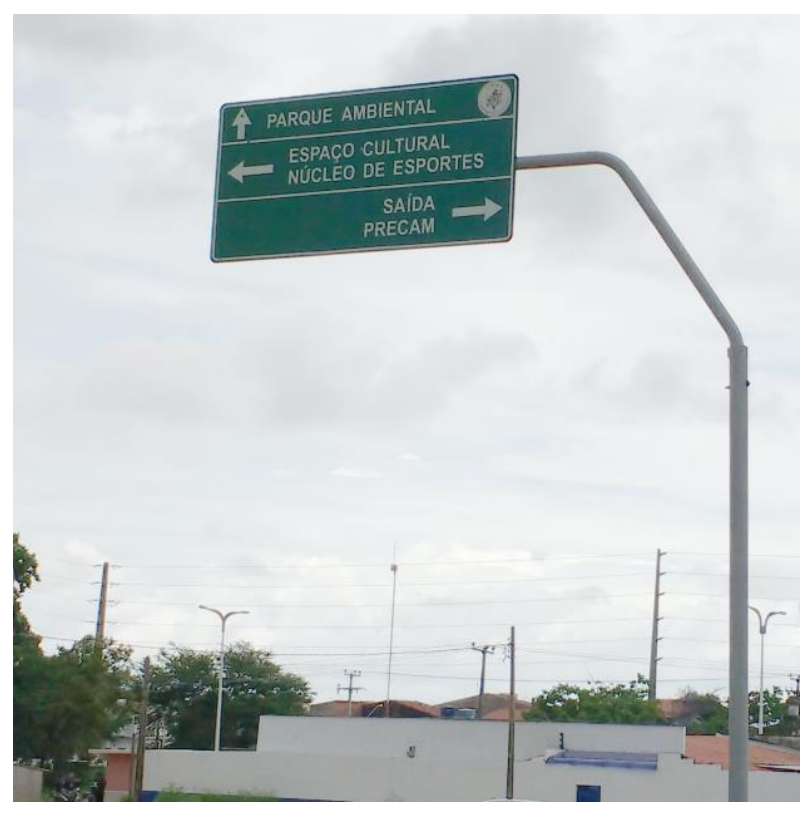

Figura 2- placas de sinalização. Fonte: arquivo pessoal

\section{4- Infografia}

A expressão infográfico vem do inglês infographic, sendo uma junção das palavras informação e gráfico (Ribeiro, 2008, apud 
$16^{\circ}$ Ergodesign - Congresso Internacional de Ergonomia e Usabilidade de Interfaces Humano Tecnológica: Produto, Informações Ambientes Construídos e Transporte

$16^{\circ}$ USIHC - Congresso Internacional de Ergonomia e Usabilidade de Interfaces Humano Computador

CINAHPA | 2017 - Congresso Internacional de Ambientes Hipermídia para Aprendizagem.

Carvalho \& Aragão, 2012). Sendo assim, pode-se dizer de maneira simplificada que infográficos são imagens e símbolos acompanhados de texto que facilitam o entendimento de uma mensagem.

Entretanto, nem toda imagem acompanhada de texto pode ser caracterizada como infográfico. Segundo Rajamanickam (2005):

\footnotetext{
"Construir a representação visual da informação não é mera tradução daquilo que pode ser lido para aquilo que pode ser visto. Implica filtragem da informação, estabelecer relações, diferenciar padrões e representá-los de uma forma que permitam ao leitor compreender que tal informação constrói algo com significado". (Rajamanickam, 2005. p. 2)
}

Ou seja, o infográfico representa uma ideia que está inserida em um contexto, seguindo o raciocínio de seu autor, para um melhor entendimento por parte de quem o está lendo.

Silveira (2010) ainda complementa dizendo que a diferença de um infográfico está no modo de leitura, na forma na qual nossos processos cognitivos reorganizam a mensagem.

A maioria dos autores situa a infografia entre a área de jornalismo e do design gráfico. Sua história se confunde com a história da imprensa e dos jornais impressos, ainda que fossem utilizados inicialmente apenas como complemento de alguma informação textual ou arte decorativa. Seu desenvolvimento, então, só foi possível, segundo De Pablos (1999, apud Silveira, 2010), a partir da evolução da imprensa, do desenvolvimento da cartografia, do pensamento estatístico e da ilustração científica, do surgimento de tecnologias de transmissão e impressão e das mudanças da linguagem jornalística.

Moraes (2013) divide os infográficos em 3 categorias: os infográficos explanatórios, os exploratórios e os historiográficos.

Os infográficos explanatórios "são aqueles cuja finalidade é explicar o funcionamento de determinado objeto (...)". Aqui estão incluídos os diagramas, quadros do tipo passo a passo, diagramas instrucionais ou didáticos, cineminhas etc.

Os infográficos historiográficos são aqueles que apresentam eventos históricos e sua contextualização. As chamadas linhas do tempo (timeline) exemplificam bem esta categoria.

Por último, os infográficos exploratórios que, segundo o autor, "constituem-se no nível mais simples quanto à complexidade das informações e apresentam as formas mais elementares da visualização de dados". (Moraes, 2013). São os que apresentam o conteúdo através de fotos, mapas, plantas e perspectivas com informações descritivas a respeito do objeto. Seu objetivo maior é a apresentação e descrição de um elemento. Aqui estão incluídos os mapas, vistas, plantas, perspectivas e ilustrações descritivas.

É nesta categoria que se encontra o objeto deste estudo, cujo objetivo maior é a visualização/apresentação de dados. Estes dados são os elementos do mapa que, somados a outras informações relevantes, irão apresentar o espaço da Universidade para quem o estiver lendo.

Desta forma, para o design, o infográfico é um artefato de linguagem visual capaz de unir representações gráficas como texto, imagem e forma para comunicar uma mensagem com algum sentido. Já para os frequentadores do campus, é uma forma de acessar informações de modo mais simples e preciso, auxiliando assim na tomada de decisões, autonomia e satisfação.

\section{1- Como a infografia pode auxiliar no desenvolvimento de soluções para orientação especial}

Segundo Horn (1999) "O infográfico é considerado uma unidade de comunicação autônoma, pois seu entendimento não depende de um contexto" (Horn, 1999). Sendo assim, se torna a melhor alternativa para o auxílio de pessoas que nunca tiveram nenhum contato com o assunto ou objeto de um infográfico. 
$16^{\circ}$ Ergodesign - Congresso Internacional de Ergonomia e Usabilidade de Interfaces Humano Tecnológica: Produto, Informações Ambientes Construídos e Transporte

$16^{\circ}$ USIHC - Congresso Internacional de Ergonomia e Usabilidade de Interfaces Humano Computador

CINAHPA | 2017 - Congresso Internacional de Ambientes Hipermídia para Aprendizagem.

Para Chamma e Pastorello (2007, apud Rocha \& Garone, 2014), a infografia tem o objetivo de informar as pessoas. Para os autores,

\begin{abstract}
"O principal objetivo da sinalização é este: informar os usuários não frequentes. Aqueles que não têm domínio do espaço e/ou ambiente. Nossa principal missão é tornar a visita do novo usuário confortável, prescindindo da comunicação verbal e da boa vontade de terceiros em informar". (CHAMMA \& PASTORELO, 2007. p. 158, apud Rocha \& Garone, 2014).
\end{abstract}

Para a orientação espacial, o foco de um mapa é justamente orientar pessoas que não tiveram contato com aquele espaço antes. Para elas, localizar-se e saber como chegar ao local de destino se torna seu principal objetivo.

Para Gibson (2009), "os mapas e infográficos complementam a sinalização existente e representam o espaço territorial onde o indivíduo se encontra, permitindo que o mesmo tenha autonomia para decidir suas próprias direções". Ainda de acordo com ele,
“os mapas descrevem a organização espacial dos ambientes e mostram quais relações existem entre elementos de um local e os caminhos que serão acessados para as pessoas alcançarem seus destinos. O usuário com o auxílio do mapa pode se situar no ambiente e descobrir por si só onde fica exatamente aquilo que procura". (Gibson 2009, p.100)

\section{5- Discussões e Recomendações para um projeto de infográfico para o campus universitário do Bacanga}

Para a Universidade Federal do Maranhão, ter um ambiente acessível para seus visitantes e, principalmente, para a comunidade discente é essencial para consolidar-se como instituição formadora, inclusiva e preocupada com o bemestar de seus frequentadores, assíduos ou não.

$\mathrm{O}$ wayfinding se encontra dentro de um novo campo do design denominado Design Gráfico Ambiental (Environmental Graphic Design$E G D)$, que pode ser definido, de acordo com
Scherer (2014) em uma área multidisciplinar que une arquitetura e design no planejamento dos espaços e de seus elementos gráficos (informações) em um sistema visualmente coeso, com o intuito de sinalizar, ambientar e expor.

É importante o conhecimento desses conceitos para entender o processo de tomada de decisões no deslocamento do usuário pelo espaço. Essas informações são úteis para, posteriormente, serem analisadas, hierarquizadas e transmitidas através da infografia.

Para a construção de um infográfico, levando-se em conta sua estrutura, é necessário o uso de representações gráficas como texto, imagem e forma. Também é preciso levar em conta os aspectos sintáticos e semânticos. O primeiro diz respeito à estrutura formal deles. Já o segundo se refere aos seus sentidos e significados.

Carvalho \& Aragão (2012) propõem uma metodologia baseada em três fases: concepção, execução e acabamento.

A fase de concepção compreende as etapas de definição e apropriação do tema que será abordado na peça. Nesta etapa o mais importante é compreender o assunto que será abordado e quais informações são mais relevantes sobre ele. Pode ser subdividida em: pauta e apuração e levantamento de dados.

Durante a execução, há elaboração de conteúdo e arquitetura de informação. Aqui as autoras ainda recomendam uma fundamentação teórica sobre elementos do infográfico de Horn (1999). Esse conhecimento é importante para a hierarquização das informações e para compor os elementos gráficos. Subdivide-se em: análise de similares, elaboração de conteúdo e arquitetura de informação.

Por último, a fase de acabamento, onde há a união dos textos com os elementos gráficos, ajustes, revisões e análises críticas. Também é a fase dos detalhamentos de produção. Subdivide-se nas seguintes etapas: arte-final, acabamento, revisão, publicação e análise crítica.

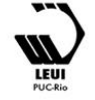


$16^{\circ}$ Ergodesign - Congresso Internacional de Ergonomia e Usabilidade de Interfaces Humano Tecnológica: Produto, Informações Ambientes Construídos e Transporte

$16^{\circ}$ USIHC - Congresso Internacional de Ergonomia e Usabilidade de Interfaces Humano Computador

CINAHPA | 2017 - Congresso Internacional de Ambientes Hipermídia para Aprendizagem.

Além desse processo, pode-se ainda utilizar o diagrama de McCandless proposto por Silveira (2010), para direcionar e avaliar características essenciais que devem constar em um projeto de infográfico.

David McCandless (apud SILVEIRA, 2010) propôs um diagrama com quatro elementos: integridade, forma, função e interestingness (relativo a "ser interessante"). Tendo por base esse diagrama, a autora desenvolveu em sua pesquisa um conjunto de quatro elementos que são essenciais em um infográfico: integridade, usabilidade, estética e conteúdo.

A integridade se relaciona com confiabilidade e nela são incluídos outros critérios, como precisão, clareza e escala.

A usabilidade está relacionada com a facilidade de uso do material é definida por cinco componentes: facilidade de aprendizado, eficiência, facilidade de memorização, índice de erros e satisfação.

A estética, que não se limita apenas à atração do olhar, mas também a um bom uso de ícones e representações que reforçam o valor da informação. Ela pode ser avaliada através da atratividade, comunicação visual e pelo valor (relacionado à qualidade da produção e impressão).

Por último, o conteúdo, que compreende à seleção e relevância das informações, as perspectivas e a completude das informações. (SIL VEIRA, 2010)

Todos esses valores, se aplicados em harmonia, permitem a construção de um infográfico preciso e eficaz, levando em conta as necessidades dos usuários e permitindo a eles se locomoverem com segurança, autonomia e tranquilidade.

De acordo com o que foi apresentado, se torna evidente a importância do conhecimento sobre wayfinding antes e durante o desenvolvimento de um projeto de infográfico, a fim de compreender como o usuário daquele espaço se comporta diante dele.
Para a construção do infográfico, é importante seguir uma metodologia eficiente que contemple desde a coleta de dados até a impressão do arquivo. Também é fundamental que posteriormente se avalie a eficácia do produto diante de seu públicoalvo.

Com os estudos realizados nesta pesquisa, propõese uma metodologia coerente com os requisitos citados acima, além de apresentar os referenciais teóricos sobre wayfinding, sinalização e infografia necessários para o desenvolvimento de um projeto nesta área.

\section{6- Desdobramentos da pesquisa}

Esse artigo é uma primeira etapa de um projeto de TCC que visa o desenvolvimento de um infográfico de auxílio à navegação em um campus universitário. No material também constará informações relevantes sobre alguns serviços e utilidades oferecidas, além das rotas do transporte público dentro da Universidade.

O objetivo é auxiliar as pessoas que frequentam a Cidade Universitária a navegar dentro daquele espaço e tomar decisões de maneira mais fácil, rápida e segura.

\section{7- BIBLIOGRAFIA}

CARVALHO, Juliana.; ARAGÃO, Isabela. 2012

Infografia: Conceito e Prática. InfoDesign, v. 9, n. 3, São Paulo: SBDI, p. $160-177$

\section{COSTA, Hermano T. Sistema de Sinalização e Wayfinding para o Centro de Ciências Exatas e Tecnologia da Universidade Federal do Maranhão- CCET UFMA. Monografia de graduação. UFMA, 2014.}

DE PABLOS, Jose Manuel. 1999.

Infoperiodismo. El Periodista como Creador de Infografia. Madrid: Editorial Sintesis

GIANELLA, Julia R.; SOUZA, Sandra. 2015

Mediações e Sense-Making: duas lógicas 
$16^{\circ}$ Ergodesign - Congresso Internacional de Ergonomia e Usabilidade de Interfaces Humano Tecnológica: Produto, Informações Ambientes Construídos e Transporte

$16^{\circ}$ USIHC - Congresso Internacional de Ergonomia e Usabilidade de Interfaces Humano Computador

CINAHPA | 2017 - Congresso Internacional de Ambientes Hipermídia para Aprendizagem.

comunicacionais do Design da Informação.

InfoDesign, v. 12, n.1, São Paulo: SBDI, p. 47-61

GIBSON, David. The wayfinding book:

Information design for public places. New

York: Princeton Architectural Press, 2009.

HORN, R. Information Design: emergence of a new profession. In: JACOBSON, R. (Org.).

Information Design. Cambridge: MIT Press, 1999.

Disponível em

<https://web.stanford.edu/ rhorn/a/topic/vl\%26id/a rtclInfoDesignChapter.html >. Acesso em 3 de

Março de 2017

MORAES, Ary. Infografia: história e projeto. São Paulo: Blucher, 2013.

MUNARI, Bruno. Design e Comunicação Visual. Lisboa, PT: Edições 70, 2006.

PACHECO, Waleska C. Sieczkowski ;

FUKUSHIMA, Kando . Aspectos informacionais do sistema de sinalização interna da UTFPR Universidade Tecnológica Federal do Paraná.. In: $10^{\circ} \mathrm{P} \& D$ Design - Congresso Brasileiro de Pesquisa e Desenvolvimento em Design, 2012, São Luíz do Maranhão. ANAIS do $12^{\circ}$ Congresso Brasileiro de Pesquisa e Desenvolvimento em Design, 2012., 2012

RAJAMANICKAM, Venkatesh. 2005.Infographics Seminar Handout.

Disponível em <

http://www.schrockguide.net/uploads/3/9/2/2/3922

67/infographic_handout.pdf $>$. Acesso em 8 de Março de 2017

ROCHA, M. A. ; GARONE, P. M. C. . Infografia na sinalização: o design da informação e os serviços oferecidos pela Universidade Federal do Espírito Santo aos ingressantes do campus de Goiabeiras.. In: ERGODESIGN 2014, 2014, Joinville. ERGODESIGN-USIHC Anais 2014, 2014

SCHERER, Fabiano de Vargas; "DESIGN

GRÁFICO AMBIENTAL: REVISÃO E DEFINIÇÃO DE CONCEITOS", p. 1-12 . In:
Anais do $11^{\circ}$ Congresso Brasileiro de Pesquisa e Desenvolvimento em Design [= Blucher Design Proceedings, v. 1, n. 4]. São Paulo: Blucher, 2014.

SILVEIRA, L. H. Y. da. Modelo de caracterização de infográficos: uma proposta para análise e aplicação jornalística. 2010. Tese de Doutorado. Universidade de São Paulo.

VISOCKY O'GRADY, Jennifer; VISOCKY O'GRADY, Kenneth. The information design handbook. Cincinnati, Ohio: How Books, 2008
Realização:

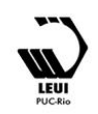

